\title{
É eticamente aceitavel o uso de recém - cadaveres no ensino de procedimentos médicos?
}

\author{
Is the use of newly deceased ethically acceptable for teaching medical \\ procedures?
}

José MARQues FILHO ${ }^{1}$

R E S U M O

\begin{abstract}
A utilização de recém-cadáveres no ensino de procedimentos médicos ocorre com frequência desconhecida. Na área cirúrgica o treinamento de habilidades tem fundamental importância devido à necessidade de procedimentos invasivos próprios dos cirurgiões. Existem raras publicações sobre esse procedimento na área de Bioética, mas é fundamental que esta discussão e reflexão sejam feitas nos departamentos de cirurgia dos hospitais de ensino. A realização de procedimentos em recém-cadáveres deve ser encarada como exceção e ser precedida, obrigatoriamente, de autorização dos familiares.
\end{abstract}

Descritores: Bioética. Ensino. Médicos. Materiais de ensino. Cadáver.

A Prática de utilização de recém - cadáveres, ou seja, paciente com óbito recente, no ensino de procedimentos médicos é um tema pouco discutido na literatura. Existem fortes evidencias que ocorre com certa frequência em nosso meio, e também em outros países, porém raramente se admite tal prática.

O curso médico consta de um programa cujo escopo é a aquisição, pelo profissional em formação, de uma base cognitiva especializada, habilidades, competências e valores profissionais. As normas preconizadas pelas Diretrizes Curriculares para os Cursos de Graduação em Medicina' são no sentido de prover o profissional, no final do curso, de uma capacitação ampla, no sentido de atuar em todos os níveis de assistência.

A Residência Médica é uma forma de pós-graduação onde o médico cumpre um programa de treinamento assistido e orientado por preceptores, onde a aquisição de habilidades é parte fundamental na formação técnica do profissional. O rol de habilidades necessárias para uma boa formação profissional é assunto discutido regularmente nos encontros de educação médica, sendo constantemente atualizado em virtude dos avanços da ciência e da tecnologia na área da saúde.

Há certo consenso que procedimentos tais como sutura simples, drenagem de abscesso, punções e reanimação cárdiorrespiratória, são exemplos de habilidades mínimas obrigatórias para o recém formado. Outras habilidades mais específicas, em geral, fazem parte do treinamento de especialistas.

$\mathrm{Na}$ área cirúrgica, o treinamento de habilidades ganha fundamental importância, pois além de uma boa formação médica, o cirurgião deve treinar habilidades para procedimentos invasivos obrigatórios em sua pratica diária. Este importante tema, do ponto de vista bioético, tem sido pouco abordado.

Vale a pena chamarmos atenção para o fato que esses procedimentos são geralmente visto por boa parte dos estudantes como procedimentos corriqueiros e sem maiores dilemas morais. Pior ainda, geralmente ocorrem às escondidas, atrás de biombos ou em salas fechadas, sem o consentimento dos familiares e, muitas vezes, sem a adequada orientação de um docente ou preceptor ${ }^{2}$.

Uma questão importante que também tem sido pouco discutida é o impacto e os riscos para os pacientes submetidos a procedimentos invasivos por estudantes de graduação ou residentes em inicio de treinamento. Um interessante estudo feito por Chen et al. ${ }^{3}$ demonstrou incidência de $18 \%$ de traumas orais, na realização de entubação orotraqueal, quando realizado por profissionais em treinamento. Não existem dúvidas entre os autores sobre a obrigatoriedade de treinamento em modelos, antes da prática em pacientes.

$\mathrm{Na}$ área didática de procedimentos invasivos, existem varias alternativas que têm sido utilizadas ao longo da historia do ensino médico. Um dos procedimentos mais antigos é o treinamento em animais. Embora tradicional nas Escolas de Medicina Brasileiras, o treinamento em animais somente foi oficializado no Brasil com a criação do primeiro curso de pós - graduação de cirurgia experimental e bases gerais da cirurgia na Faculdade de Medicina de Botucatu / SP, na década de setenta do século passado, pelo professor Hossne ${ }^{4}$. Nos dias de hoje tor-

1. Doutorando em Bioética - Centro Universitário São Camilo-SP. Especialista em Reumatologia e Clinica Médica. Conselheiro do Conselho Regional de Medicina do Estado de São Paulo. 
nou-se rotina a prática de treinamento para procedimentos videolaparoscópicos em animais.

Outras alternativas são possíveis, como manequins simuladores, introduzidos no treinamento de habilidades médicas desde a década de sessenta do século passado $^{5}$. Pode-se afirmar que hoje existem recursos tecnológicos perfeitamente capazes de substituir, com alto grau de fidelidade, o treinamento em animais e humanos.

Em relação à utilização de recém-cadáveres para treinamento de procedimentos invasivos, do ponto de vista bioético, somente tem fundamentação através do adequado e indispensável consentimento da família. Estudos têm demonstrado que, quando esclarecida, em cerca de um terço dos casos há o consentimento familiar para treinamento didático em recém-cadáveres ${ }^{6}$. A questão ética que deve merecer reflexão é se há justificativa suficiente para se submeter a família ao constrangimento de concordar com a realização de procedimentos com finalidade didática, após todo trauma emocional com a morte recente de um pessoa querida. Nossa primeira tendência é dizer não. Mas esse assunto deve ser levantado e discutido nos meios acadêmicos, no sentido educativo da formação ética do jovem médico e de alargarmos e aprofundarmos nossa visão enquanto professores e médicos assistentes. Alguns autores argumentam que procedimentos em recém - cadáveres não trazem nenhum dano adicional ao falecido. De fato não trazem, mas não podemos esquecer que podem trazer danos aos familiares.

Discute-se hoje em Bioética a extrema importância do respeito ao cadáver, que embora juridicamente perca o status de cidadão, merece tratamento respeitoso por toda biografia e significado para aqueles que com ele conviveram. Há hoje plena consciência do impacto emocional que o falecimento de uma pessoa traz aos seus familiares, inclusive com implantação de programas e treinamentos dos profissionais da área da saúde visando a prestar assistência aos familiares através da agilização de trâmites burocráticos ${ }^{7}$. Concordamos com Gomes et al. ${ }^{2}$, quando afirmam que "faz parte do ethos da sociedade brasileira a compreensão da competência da família decidir sobre o cadáver". Comparam a presente situação com aquela relativa a obrigatoriedade do consentimento da família para a doação de órgãos para transplante. As normas éticas brasileiras não fazem referencias especificas a situação aqui discutida. Entretanto, o Código de Ética médica determina que é vedado ao médico procedimentos sem autorização do paciente ou de seu representante legal. O cadáver, do ponto de vista estritamente jurídico, não tem representante legal, mas, o direito da família decidir sobre seus mortos tem sido uma constante na prática da Bioética Clínica entre nós. Diversos estudos tem demonstrado a fundamental importância da formação ética dos profissionais da saúde e seus reflexos no cotidiano do povo brasileiro ${ }^{8}$. Em relação às normas legais, pode-se citar o artigo 212 do Código Penal - Dos crimes contra o sentimento religioso e contra o respeito aos mortos - qualifica-se como crime o vilipendio a cadáveres ou suas cinzas, com pena de reclusão de um a três anos e multa.

Finalizando esta breve reflexão, o tema aqui abordado deve ser discutido nos meios acadêmicos, principalmente nas instituições de ensino de graduação e pós graduação visando o adequado respeito à dignidade das pessoas e o respeito devido aos cadáveres, principalmente quando utilizados para estudos de anatomia ou procedimentos médicos. A realização de procedimento invasivo em recém - cadáveres deve ser encarada como exceção dentro do treinamento profissional, e, obrigatoriamente, ser precedida de autorização familiar. A discussão e reflexão sobre esse tema devem ser estimuladas com regular frequência nos serviços onde existem atividades de graduação e pós-graduação médica.

\title{
A
}

\begin{abstract}
The use if newly deceased for teaching medical procedures occurs with an unknown frequency. In the surgical area the training of skills has a fundamental importance due to the need of invasive procedures inherent to the surgical practice. There are rare publications about this issue in Bioethics, but it is fundamental that this discussion and pondering be done in the surgery departments of the teaching hospitals. The performance of procedures in newly deceased must be faced as an exception and it must be mandatorily preceded by family authorization.
\end{abstract}

Key words: Bioethics. Teaching. Physicians. Teaching materials. Cadaver.

\section{REFERÊNCIAS}

1. Brasil. Conselho Nacional de Educação. Câmara de Educação Superior. Resolução CNE/CSE n 4, de 07 de novembro de 2001 Institui Diretrizes Curriculares Nacionais do Curso de Graduação em Medicina. Diário Oficial da União. Brasília, 09 de novembro de 2001: Seção 1, p.38.

2. Gomes AP, Rego S, Palácios M, Siqueira-Batista R. Análise bioética do uso de recém-cadáveres na aprendizagem prática em medicina. Rev Assoc Med Bras. 2010;56(1):11-6.
3. Chen JJ, Susetio L, Chao CC. Oral complications associated with endotracheal general anesthesia. Ma Zui Xue Za Zhi. 1990:28(2):163-9.

4. Vieira S, Hossne WS. Experimentação com seres humanos. São Paulo: Moderna; 1987

5. Cooper JB, Taqueti VR. A brief history of the development of mannequin simulators for clinical education and training. Qual Saf Health Care. 2004;13(Suppl 1:i11-8. Erratum in Qual Saf Health Care. 2005;14(1):72 
6. Olsen J, Spilger S, Windisch T. Feasibility of obtaining family consent for theaching cricothyrothomy on the newly dead on the emergency department. Ann Emerg Med. 1995;25(5):660-5.

7. Novaes LCG, Machado Filho JRS, Novaes MRCG. Razões legais na atenção ao cadáver e nas autópsias. Rev saúde Dist Fed. 2004;15(1/ 2):87-103.

8. Gomes JCM. O atual ensino da ética para os profissionais de saúde e seus reflexos no cotidiano do povo brasileiro. Bioética. 1996;4(1):53-64.
Recebido em 15/10/2011

Aceito para publicação em 16/11/2011

Conflito de interesse: nenhum

Fonte de financiamento: nenhum

\section{Como citar este artigo:}

Marques Filho J. É eticamente aceitável o uso de recém-cadáveres no ensino de procedimentos médicos ?. Rev Col Bras Cir. [periódico na Internet] 2012; 39(1). Disponível em URL: http://www.scielo.br/rcbc

Endereço para correspondência:

José Marques Filho

E-mail: filho.jm@bol.com.br 